\title{
Review
}

\section{Molecular Mechanism of Neuronal Plasticity: Induction and Maintenance of Long-Term Potentiation in the Hippocampus}

\author{
Eishichi Miyamoto ${ }^{1, *}$ \\ ${ }^{I}$ Department of Electrical Engineering and Bioscience, Graduate School of Science and Engineering, Waseda University, \\ Tokyo 196-8555, Japan
}

Received March 14, 2006

\begin{abstract}
Recent studies have demonstrated that activation of enzymes can be observed in living cells in response to stimulation with neurotransmitters, hormones, growth factors, and so forth. Thus, the activation of enzymes was shown to be closely related to the dynamic states of various cell functions. The development of new experimental methodologies has enabled researchers to study the molecular basis of neuronal plasticity in living cells. In 1973, Bliss and his associates identified the phenomena of long-term potentiation (LTP). Since it was thought to be a model for neuronal plasticity such as learning and memory, its molecular mechanism has been extensively investigated. The mechanism was found to involve a signal transduction cascade that includes release of glutamate, activation of the NMDA glutamate receptors, $\mathrm{Ca}^{2+}$ entry, and activations of $\mathrm{Ca}^{2+} /$ calmodulin-dependent protein kinases (CaM kinases) II and IV and mitogen-activated protein kinase (MAPK). Consequently, AMPA glutamate receptors were activated by phosphorylation by $\mathrm{CaM}$ kinase II, resulting in an increase of $\mathrm{Ca}^{2+}$ entry into postsynaptic neurons. Furthermore, activation of CaM kinase IV and MAPK increased phosphorylation of CREB (cyclic AMP response element binding protein) and expression of c-Fos by stimulation of gene expression. These results suggest that LTP induction and maintenance would be models of short- and long-term memory, respectively.
\end{abstract}

Keywords: hippocampus, long-term potentiation, learning and memory, protein phosphorylation, gene expression

\section{Introduction}

In recent years, studies on the molecular mechanisms of the higher nervous activities of mammals have been initiated. To elucidate the dynamic state of cellular functions, the molecular mechanisms of the functions should be observed in living cells. The activation of receptors, enzymes, and gene expression must be analyzed in the in situ cells and it must be determined how these activations are related to specific cellular functions. In this sense, it may be important to determine the time courses for the activations of functional compo-

\footnotetext{
*Corresponding author. Present affiliation: Kumamoto University (Professor Emeritus) emiyamot@gpo.kumamoto-u.ac.jp Published online in J-STAGE

DOI: $10.1254 /$ jphs. CPJ06007X
}

Invited article nents in relation to the manifestations of specific cellular functions. According to this concept, we have studied $\mathrm{Ca}^{2+}$-dependent reactions in living cells such as established cell lines, primarily cultured cells, cultured passage cells, and tissue slices $(1-30)$ (Table 1). Effects of endogenous components such as neurotransmitters, hormones, growth factors, and so on were examined by adding them to the culture medium. Since the elucidation of the in vivo cellular functions would not be an easy task in most cases, these approaches were thought to be appropriate means to closely approximate the temporal changes in the dynamic state of specific cellular functions.

In 1973, Bliss and his associates, as described below, reported that tetanic stimulation of the perforant pathway of presynaptic fibers resulted in high responses of granule cells of postsynaptic neurons to electric stimulation. The experiments were conducted in vivo with 
Table 1. Activation of CaM kinases I, II, and IV and MAPK in response to receptor stimulation and cellular functions

\begin{tabular}{rllll}
\hline & Cell & Stimuli & Regulation & Reference \\
\hline 1) & 3Y1 fibroblast & EGF, PDGF & activation* & 1 \\
2) & NG108-15 cell & bradykinin & activation, gene expression & 2 \\
$3)$ & Hippocampal cultured neurons & glutamate & activation & $3-8$ \\
$4)$ & Hippocampal slices & tetanic stimulation & LTP & $9-13$ \\
$5)$ & Astrocyte & glutamate & gene expression & $14-15$ \\
$6)$ & Cultured adrenal medulla cells & acetylcholine & catecholamine synthesis and release & $16-18$ \\
$7)$ & PC12 cells & ionomycin & differentiation of neurons & 19 \\
$8)$ & Insulinoma cell (MIN6 cell) & glucose, ionomycin & insulin secretim, gene expression & $20-23$ \\
$9)$ & GH3 cells & TRH, bromocriptine & activation, apoptosis & 24,25 \\
$10)$ & HEC-1B & hCG, PGE2 & activation, gene expression & 26,27 \\
$11)$ & $\alpha$ T3-1 cells & D2 agonist & gene expression & 28,29 \\
$12)$ & L $\beta$ T2 cells & activin, GnRH & gene expression & 30 \\
\hline
\end{tabular}

*enzyme activation

Table 2. Models for neuronal plasticity

\begin{tabular}{ll}
\hline & Reference \\
\hline 1) Development of neurons in visual cortex & 31 \\
in response to light stimulation & 32 \\
2) Sensitization of synaptic transmission & \\
by long-term habituation in Aplysia & 33 \\
3) Fear conditioning in amygdala & \\
(association learning) & 34 \\
4) Spatial learning in hippocampus & 35 \\
5) Procedural memory in striatum and cerebellum & 36 \\
6) Olfactory memory formation in olfactory bulb & 37 \\
7) Eyeblink conditioning in cerebellum &
\end{tabular}

rabbits. They called the effect long-term potentiation (LTP) because the elevation of the postsynaptic potential or current continued for a long time.

Mammalian brains are flexible, being able to change their functions and structures in response to internal and external stimuli. These kinds of phenomena are called neuronal plasticity. Although it is important that neuronal plasticity is studied in human beings, it may not be possible due to their complicated systems. Therefore, more simple models have been created in animals and these models have been used to try to elucidate the molecular mechanisms involved in neuronal plasticity $(31-37)$ (Table 2). Of course, each study presented here has been extensively performed and therefore cannot been described in detail in this review, but I will summarize the important aspects of these studies. LTP in the hippocampus was considered to be important for elucidating the molecular mechanism of learning and memory because these processes may be based on longlasting potentiation of synaptic efficacy $(38-46)$.
At the end of the 1980s, a number of inhibitors, including receptor inhibitors, $\mathrm{Ca}^{2+}$ chelators, calmodulin antagonists, and protein kinase inhibitors, were found to suppress LTP in the CA1 area of the hippocampus. Microinjection of a peptide of protein kinase C (PKC) inhibitory domain, calmidazolium (a calmodulin antagonist), and a peptide of $\mathrm{Ca}^{2+} /$ calmodulin-dependent protein kinase (CaM kinase) II inhibitory domain into pyramidal cells of the CA1 area of the hippocampus inhibited the induction of LTP by tetanic stimulation $(45,46)$.

In the 1990s, various knockout mice were produced by the gene-targeting method to examine which component is important for induction of LTP. NMDA glutamate receptors-, $\mathrm{PKC} \gamma$ subunit-, and CaM kinase II $\alpha$ subunit-deficient mice showed both impairment of LTP induction using hippocampal slices and lack of spatial learning using whole mice. These results suggested that LTP is correlated with spatial learning of mice and that the components deficient in these mice are involved in LTP induction.

However, the above result provided no evidence that the enzyme activity of CaM kinase II itself is involved in LTP. Molecular mechanisms of LTP induction and maintenance have not separately been elucidated. The present review provides a brief summary of historical and recent findings about the molecular mechanisms of LTP and focuses on our findings of LTP induction and maintenance.

\section{LTP induction}

\section{Inhibitors}

At the end of the 1980s, LTP was thought to be induced in the activation of postsynaptic neurons. 
Table 3. Inhibitors that suppress LTP induction

\begin{tabular}{lll}
\hline Inhibitor & $\begin{array}{l}\text { LTP } \\
\text { impairment }\end{array}$ & Reference \\
\hline NMDA receptor inhibitors & $(+)$ & 47 \\
$\mathrm{Ca}^{2+}$ chelator & $(+)$ & 48 \\
Calmodulin antagonist & $(+)$ & 49 \\
PKC (19-31) inhibitory domain & $(+)$ & 49 \\
H7 & $(+)$ & 49 \\
CaMKII (273 - 302) inhibitory domain & $(+)$ & 50 \\
KN62 & $(+)$ & 51 \\
\hline
\end{tabular}

$(+)$ means LTP impairment.

Various inhibitors were added to the culture medium or directly into pyramidal cells of the CA1 area of the hippocampus, and then LTP was induced. As shown in Table $3(47-51)$, the addition of NMDA glutamate receptor inhibitors (47), $\mathrm{Ca}^{2+}$ chelator (48), calmodulin antagonists (49), and protein kinase inhibitors such as PKC inhibitory domain, H7 (49), CaM kinase II inhibitory domain (50), and KN-62 (51) inhibited LTP induction. Thus, the induction of LTP in the CA1 area of the hippocampus requires activation of NMDA glutamate receptors, the entry of $\mathrm{Ca}^{2+}$ into postsynaptic neurons, and activation of protein kinases, especially CaM kinase II and PKC.

\section{Activation of CaM kinase II}

LTP was induced by application of theta-burst patterned stimulation to hippocampal slices and organotypic cultures (9). In each slice, two stimulation electrodes were placed in the stratum of the CA1 area. Stimulation was applied simultaneously to the two inputs. After the induction of LTP, the CA1 area of the hippocampus was dissected and homogenized in buffer containing a detergent and protease inhibitors, a PKC inhibitory peptide, and protein phosphatase inhibitors. The supernatant was assayed to determine CaM kinase II activity. Low-frequency stimulation was given to control slices.

As shown in Fig. 1, the induction of LTP resulted in increases in both the $\mathrm{Ca}^{2+} / \mathrm{CaM}$-independent and $\mathrm{Ca}^{2+} / \mathrm{CaM}$-dependent activities of CaM kinase II towards the substrates syntide 2 and synapsin I. The effect could be detected as early as $3-5 \mathrm{~min}$ after stimulation and was still present $60 \mathrm{~min}$ later. Prior to stimulation, the slices were treated with AP5, a specific inhibitor of the NMDA glutamate receptor. Under these conditions, LTP was not induced and no elevation of the CaM kinase II activity was observed.

Hippocampal slices were prelabeled with $\left[{ }^{32} \mathrm{P}\right]$ orthophosphate for $30 \mathrm{~min}$ and then stimulated to induce LTP
(10). Incorporation of $\left[{ }^{32} \mathrm{P}\right]$ phosphate into the $\alpha$ and $\beta$ subunits of CaM kinase II was determined in the LTPinduced and control slices (Fig. 1). Autophosphorylation of both the $\alpha$ and $\beta$ subunits increased during the induction of LTP. The treatment of slices with AP5 prevented the induction of LTP and abolished the increase in autophosphorylation of CaM kinase II. It was conclusively shown that $\mathrm{CaM}$ kinase II was activated during LTP induction by autophosphorylation of the enzyme. The increase in the $\mathrm{Ca}^{2+} / \mathrm{CaM}$-dependent activity of $\mathrm{CaM}$ kinase II suggests that there is an increase in the amount of CaM kinase II protein during the process of LTP induction.

\section{Mutant mice}

Mutant mice were produced by the gene targeting method. The learning and memory abilities of these mice were determined, and the excised hippocampal slices were examined for LTP induction (Table 4). The mice deficient in NMDA receptors $\varepsilon 1$ (52) and 1 (53), CaM kinase II $\alpha$ subunit $(54,55), \mathrm{PKC} \gamma$ subunit (56), and Fyn (57) showed both impairment of learning and memory and of impairment of LTP induction, although PKC $\gamma$ induction was normal. In the case of cyclic AMP response element binding protein (CREB)-deficient mice, LTP induction decreased more rapidly than in the control mice (58). These results indicate that the activation of NMDA glutamate receptors, CaM kinase II, and PKC and the involvement of Fyn and activation of CREB are required for LTP induction. On the other hand, as Fyn-deficient mice showed abnormal brain morphology, it may be questionable that Fyn is directly involved in LTP induction. As described below, CREB activation by phosphorylation was shown to be associated with LTP induction.

Tsien and his associates $(59,60)$ more clearly demonstrated the close relationship between LTP and learning ability of animals by employing an elegant technique. First of all, they produced transgenic mice by the expression of NMDA receptors in the CA1 area of the hippocampus. These transgenic mice had greater spatial learning ability than the control mice. As their next experiment, they produced mice whose CA1 area was deficient in NMDA receptors by administering the animals doxocycline, an antibiotic. These mutant mice showed the impairment of spatial learning in comparison to control mice.

These experiments using mutant mice indicate that the NMDA glutamate receptors and CaM kinase II are important for LTP induction and that LTP is closely related to spatial learning. 
A

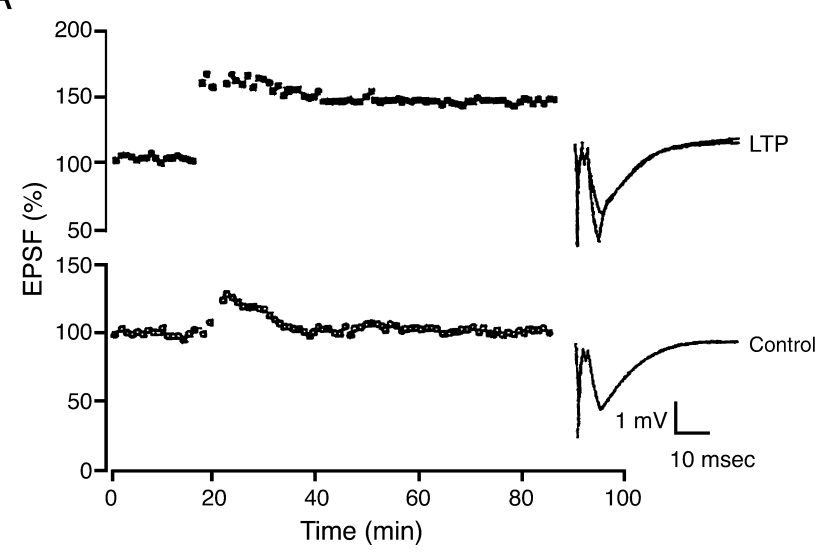

C

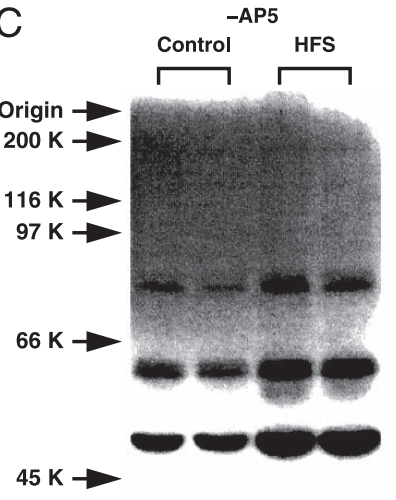

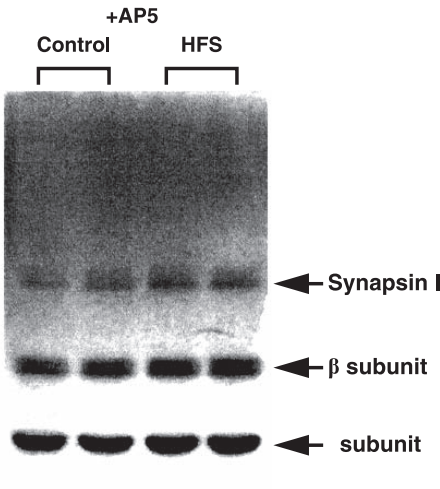

Front

B

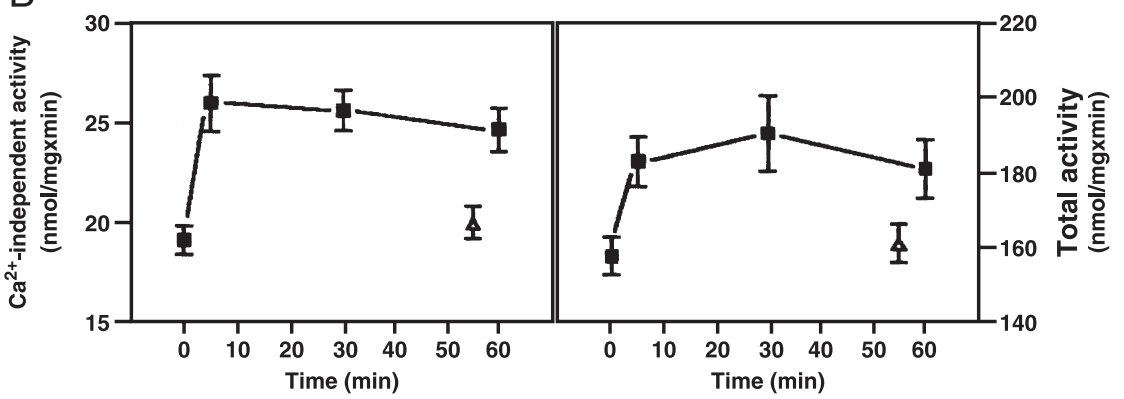

Fig. 1. The long lasting increases in $\mathrm{Ca}^{2+}$ /CaM-independent and dependent activities and autophosphorylation of CaM kinase II $\alpha$ and $\beta$ subunits during LTP (HFS) induction. A: the changes in synaptic efficacy by theta burst stimulation or low frequency stimulation. B: the levels of $\mathrm{Ca}^{2+}$-independent and total $\mathrm{CaM}$ kinase II activities determined in CA1 areas of control slices (open square) and stimulated slices (filled squares) and low frequency stimulation (open triangles). C: increased autophosphorylation of CaM kinase II $\alpha$ and $\beta$ subunits. Modified from refs. 9 and 10.
Table 4. Findings on mutant mice

\begin{tabular}{llll}
\hline Deficient & $\begin{array}{l}\text { LTP } \\
\text { impairment }\end{array}$ & $\begin{array}{l}\text { Learning } \\
\text { impairment }\end{array}$ & Reference \\
\hline NMDA receptor $\varepsilon$ 1 (NR $\varepsilon$ 1) & $(+)$ & $(+)$ & 52 \\
NMDA receptor 1 (NR1) & $(+)$ & $(+)$ & 53 \\
CaM kinase II $\alpha$-subunit & $(+)$ & $(+)$ & 54,55 \\
PKC $\gamma$ & $(+)$ & $(+)$ & 56 \\
Fyn & $(+)$ & $(+)$ & 57 \\
CREB & $(+)$ & $(+)$ & 58 \\
\hline
\end{tabular}

(+) means LTP and learning impairment.

\section{LTP maintenance}

Transient activation of mitogen-activated protein kinase (MAPK) and CaM kinase IV

In a previous study, we showed that stimulation of glutamate receptors by treatment with NMDA or glutamate produced a transient increase in $42-\mathrm{kDa}$ MAPK activity as well as the $\mathrm{Ca}^{2+}$-independent form of CaM kinase II in cultured hippocampal neurons, whereas in the hippocampal slices, high frequency stimulation (HFS) resulted in a long-lasting increase in the activity of CaM kinase II (9). These observations suggest that the activation of protein kinases can be regulated in an activity-dependent manner. A Western blotting study showed that 2 min after delivering HFS to the Schaffer collateral pathway in hippocampal slices, the 42-kDa MAPK activity increased, but this activation did not persist during the entire period of LTP induction $(61,62)$. Changes were investigated in MAPK activity in dissected CA1 areas of hippocampal slices, before and after HFS delivery. Figure $2 \mathrm{~A}$ shows the time course of MAPK activities under the conditions of LTP induction and control. Immediately after HFS, substantial increases in the activity of 42-kDa MAPK, but not 44$\mathrm{kDa}$ MAPK were evident in the LTP-established slices. A peak increase in kinase activity was observed at $3 \mathrm{~min}$ after HFS, followed by rapid recovery at $10 \mathrm{~min}$, and then reversion to nearly basal levels after $30 \mathrm{~min}$. This result is similar to that reported by other investigators (61). However, in slices subjected to LFS, no increase in MAPK activity was observed. Figure 2D summarizes the statistical analyses of these results.

The changes of CaM kinase IV activity were observed during LTP. Application of HFS to Schaffer-collateral pathways reliably induced the potentiation of the fEPSP 

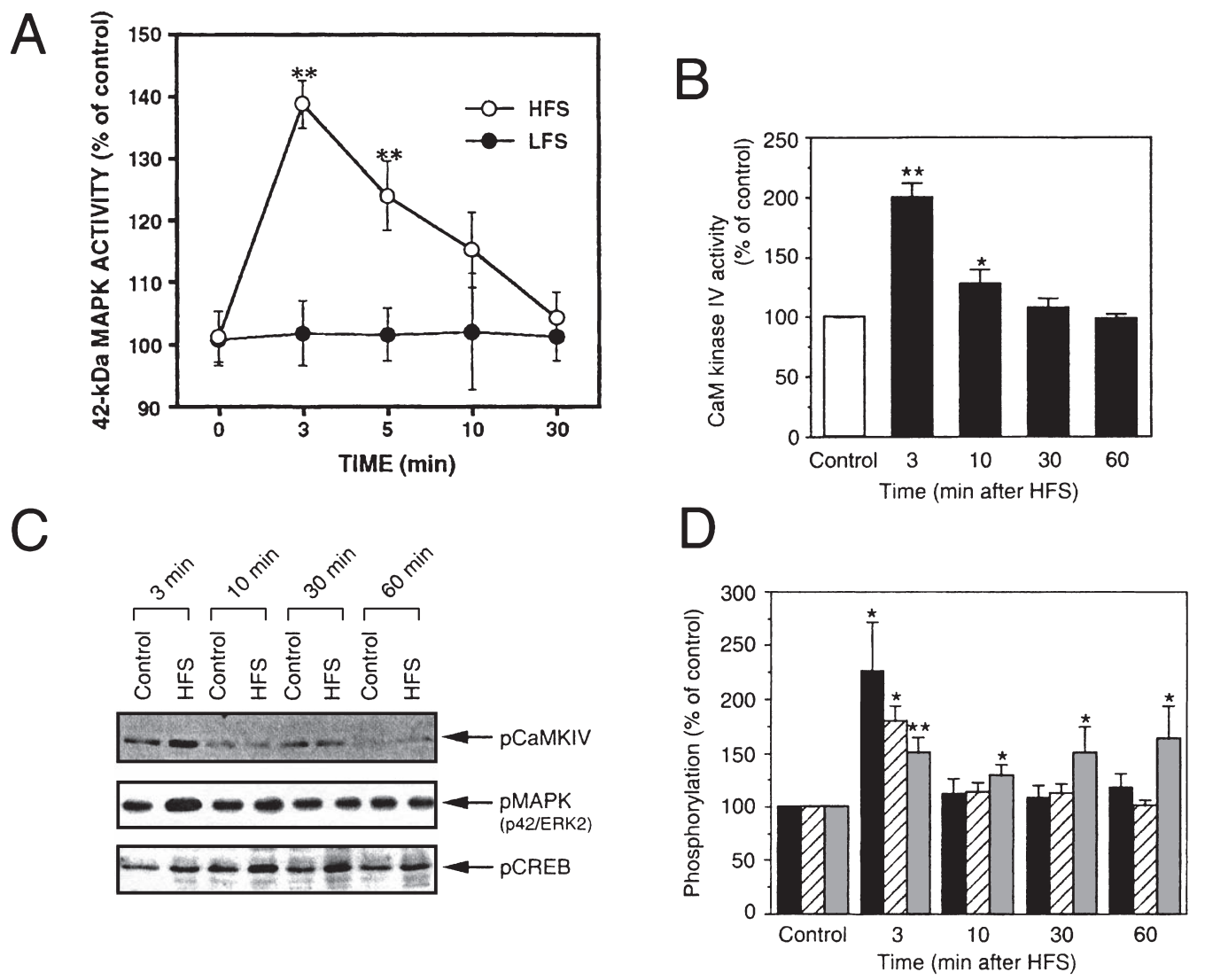

Fig. 2. Activation of MAPK and CaM kinase IV with concomitant phosphorylation of CREB during LTP. A: time course of 42-kDa MAPK activation in the slices treated with HFS (open circles) or LFS (closed circles). B: CaM kinase IV activity. C: representative autoradiograms for phosphorylated CaM kinase IV (pCaMKIV), phosphorylated p42 MAPK (pMAPK), and phosphorylated CREB (pCREB). D: quantitation of the phosphorylation of CaMKIV (black column), p42MAPK (hatched column), and CREB (gray column). Modified from ref. 11 with permission from the Society for Neuroscience (C)1999 and from ref. 13.

slope, which lasts over $60 \mathrm{~min}$ in the $\mathrm{CA} 1$ region. CaM kinase IV activity was determined 3, 10, 30, and 60 min after HFS application and was significantly increased within 3 and $10 \mathrm{~min}$, returning to basal levels within 30 min after HFS (Fig. 2A). This result was confirmed by immunoblot analysis using the anti-pT196 antibody to assess levels of CaM kinase IV phosphorylation at Thr196 (Fig. 2C), an essential site for activation of CaM kinase IV by CaM kinase kinase. Figure 2D summarizes the statistical analyses of these results. Phosphorylation of Thr196 was significantly increased 3 min after HFS and then returned to the basal level. CaM kinase IV protein levels were unchanged 3,10, and $30 \mathrm{~min}$ after HFS, although a slight but significant increase was observed 60 min after HFS, which is consistent with the previously reported result (61).

\section{CREB phosphorylation}

In contrast to activation of MAPK and CaM kinase IV (Fig. 2: A, B, and C), CREB phosphorylation detected with anti-phosho-Ser133 antibody increased 3, 10, 30, and $60 \mathrm{~min}$ after HFS, and the increased phosphorylation was sustained during LTP (Fig. 2: C and D). The protein levels of CREB were not significantly changed at any time point after HFS.

To determine the localization of activated $\mathrm{CaM}$ kinase IV in neurons, an immunohistochemical study using anti-pT196 antibody was undertaken. In control slices, moderate immunoreactivity was observed in the cytosol but was not competed by absorbance with the peptide antigen. Neuronal nuclei were not stained. In contrast, strong immunoreactivity was observed in the nuclei of neurons in HFS-applied slices, and that immunoreactivity was absent when the antibody was absorbed with the peptide antigen, indicating that it was specific. These results suggest that CaM kinase IV is activated in the nuclei of CA1 pyramidal neurons by HFS application. Specific immunoreactivity was also observed in the dendrites of the neurons because its expression was not limited to nuclei. We observed 
A

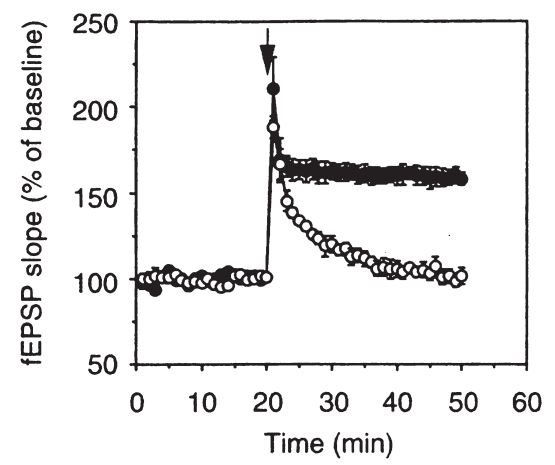

C

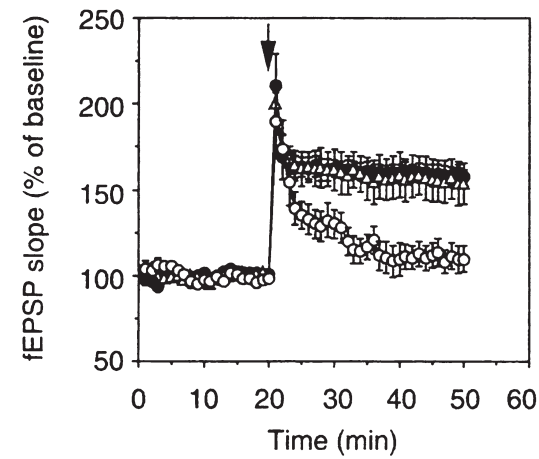

B

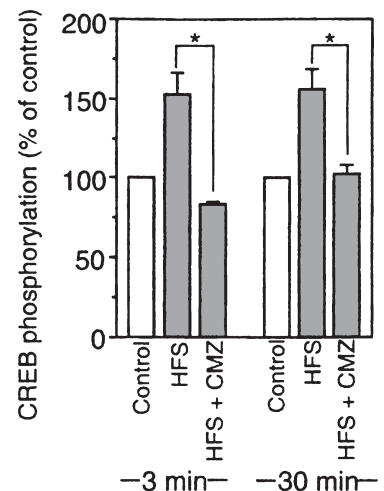

D

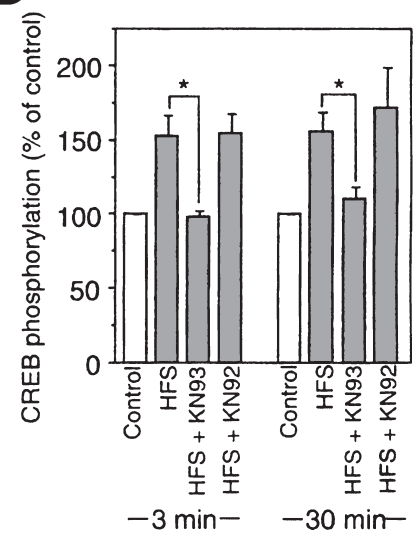

Fig. 3. Effects of calmodulin and CaM kinase inhibitors on LTP and CREB phosphorylation. A and C: changes in fEPSP slopes before and after the application of HFS (arrow) in the CA1 region. The slices were treated with no drug (closed circle), $50 \mu \mathrm{M}$ calmidazolium (open circle) in A and with no drug (closed circle), $50 \mu \mathrm{M}$ KN93 (open circle), or $50 \mu \mathrm{M}$ KN92 (open triangle) in C. B and D: quantitation of CREB phosphorylation. ${ }^{*} P<0.05$. CMZ, calmidazolium. Modified from ref. 13.

slight expression of CaM kinase IV in the cytosols and dendrites of cultured neurons.

Effects of calmodulin antagonist and CaM kinase inhibitor on LTP and CREB phosphorylation

Because it was reported that CaM kinase IV was the major CREB kinase in the response to neuronal stimulation in cultured rat hippocampal neurons $(6,7)$, it was examined whether it functioned as a CREB kinase during LTP. To inhibit CaM kinase IV activity, we used calmidazolium, a calmodulin antagonist, and KN93, a $\mathrm{CaM}$ kinase inhibitor. Both inhibitors were previously shown to inhibit CaM kinase IV activity in cultured rat hippocampal neurons (7). The application of calmidazolium (Fig. 3A) or KN93 (Fig. 3C) inhibited induction of LTP, possibly by inhibiting CaM kinase II. Calmidazolium and KN93 did significantly inhibit CaM kinase IV phosphorylation without having any effect on p42 MAPK phosphorylation. HFS-induced CREB phosphory- lation was, however, significantly inhibited by both compounds 3 and 30 min after HFS (Figs. 3: B and D). By contrast, KN92, an inactive compound similar to KN93, affected neither LTP induction nor CREB phosphorylation (Figs. 3: C and D), indicating specific inhibition by KN93. These results demonstrate a positive correlation between CaM kinase IV activation and CREB phosphorylation and are consistent with the idea that CaM kinase IV functions as a CREB kinase during HFS-induced LTP.

Likewise, the effects of an MEK inhibitor on LTP and CREB phosphorylation were examined. U0126, a specific MEK inhibitor, at a concentration that inhibits MAPK did not inhibit LTP induction. In fact, UO126 did not inhibit CREB phosphorylation 3 min after HFS, but did inhibit CREB phosphorylation $30 \mathrm{~min}$ after HFS. The MAPK cascade is thought to be involved in CREB phosphorylation through the activation of $\mathrm{p} 90$ ribosomal S6 kinase 2 (RSK2). 
A
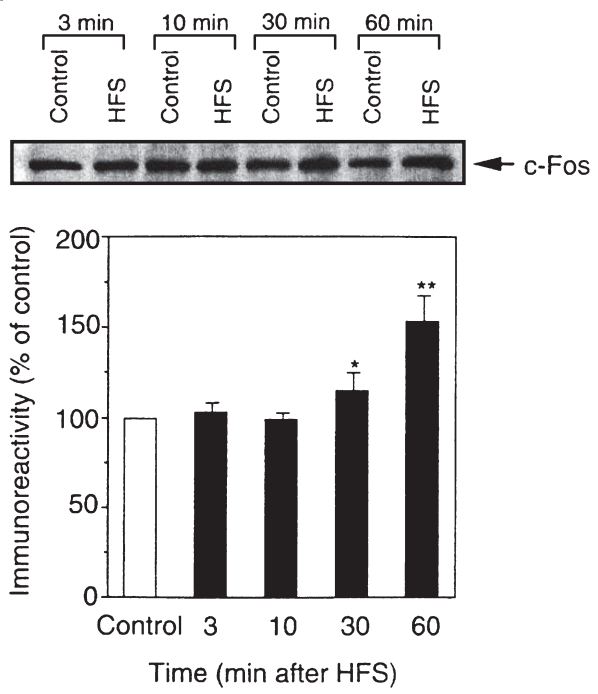

B
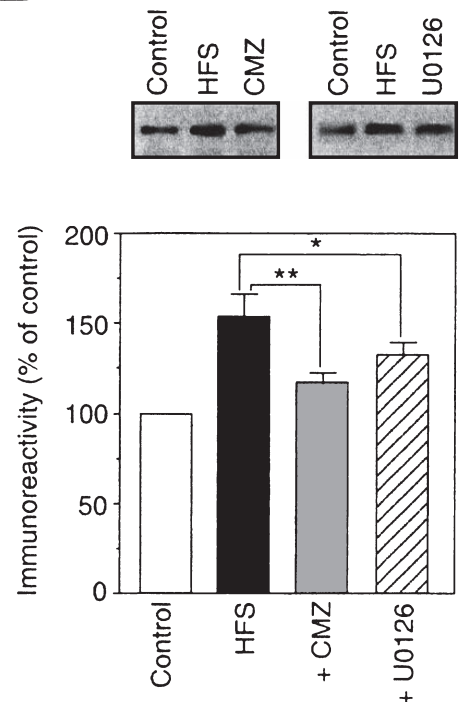

Fig. 4. Expression of c-Fos during LTP. A: c-Fos expression after application of HFS. ${ }^{*} P<0.05$, $* * P<0.01$. B: effects of protein inhibitors on c-Fos expression. The slices were treated with no drug (control), $50 \mu \mathrm{M}$ calmidazolium (CMZ), or $10 \mu \mathrm{M}$ U0126. Modified from ref. 13 .

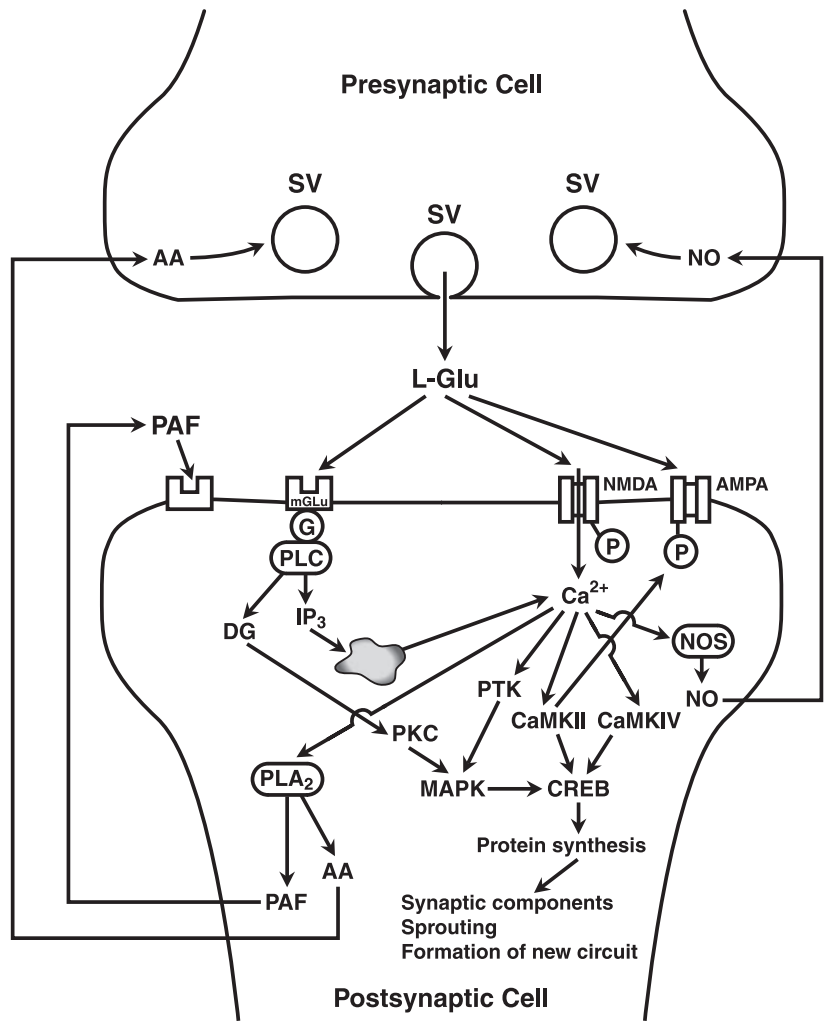

Fig. 5. Possible hypothesis for LTP induction and maintenance, which are models for short and long-term memory, respectively. SV, synaptic vesicle; PAF, platelet-activating factor; G, GTP-binding protein; PLC, phospholipase C; CaMKII, CaM kinase II; CaMKIV, CaM kinase IV; PTK, phosphotyrosine kinase; NOS, nitric oxide synthase; TF, transcription factor; AA, arachidonic acid.
These results suggest that CaM kinase IV and MAPK pathways act as CREB kinases in LTP. The results also indicate that $\mathrm{CaM}$ kinase IV starts as a CREB kinase from a relatively early stage of LTP, whereas MAPK functions at a later stage during the time course of LTP.

\section{Stimulation of c-Fos expression during LTP}

Since it was elucidated that CREB phosphorylation is activated during LTP, it was examined whether gene expression induced by the CRE-activated pathway is stimulated. As shown in Fig. 4A, the expression of the c-Fos protein was unchanged 3 and $10 \mathrm{~min}$ after LTP induction and then significantly increased 30 and $60 \mathrm{~min}$ after LTP. These observations suggested that phosphorylated CREB stimulated the expression of c-Fos. It was also confirmed that the stimulated expression of c-Fos was inhibited by the addition of the calmodulin antagonist calmidazolium and the MEK inhibitor U0126 (Fig. 4B). The results suggest that CREB-mediated gene expression is stimulated through phosphorylation of CREB by activation of CaM kinase IV and MAPK.

\section{Molecular mechanism of LTP induction and mainte- nance}

The summarized hypothesis for LTP induction and maintenance is shown in Fig. 5. First of all, L-glutamate is released as the neurotransmitter from presynaptic neurons. The released L-glutamate specifically stimulates NMDA glutamate receptors. Consequently, $\mathrm{Ca}^{2+}$ enters the presynaptic neurons through activated 
NMDA glutamate receptors. CaM kinase II is activated by calmodulin in the presence of the elevated concentration of $\mathrm{Ca}^{2+}$. Activated CaM kinase II can phosphorylate AMPA glutamate receptors with concomitant activation. More $\mathrm{Ca}^{2+}$ enters postsynaptic neurons through activated AMPA glutamate receptors. Thus, LTP induction is produced as a event in postsynaptic neurons.

On the other hand, to produce LTP maintenance, stimulation of gene expression is thought to be required in addition to short activation of an enzyme such as $\mathrm{CaM}$ kinase II and subsequent $\mathrm{Ca}^{2+}$ entry. As presumed, MAPK and CaM kinase IV, which can be involved in stimulation of gene expression, were found to be activated during LTP. We previously reported that MAPK activation is produced by stimulation of glutamate receptors using cultured hippocampal neurons (4). Glutamate receptors involved included both NMDA and metabotropic receptors. The latter pathway was thought to require the activation of PKC. The target transcription factor for MAPK and CaM kinase IV could be CREB, as shown in Figs. 2 and 3. Furthermore, expression of c-Fos protein was stimulated by activation of MAPK, CaM kinase IV, and CREB during LTP. These results are consistent with the hypothesis that LTP maintenance requires stimulation of gene expression and subsequent protein synthesis. This would lead to new synthesis of synaptic components, sprouting, and formation of new circuits. Reconstruction of morphological structure of synapses would be needed to form LTP maintenance and long memory. In fact, it was reported that the number of spines increases during LTP (63).

Surprisingly, activation of MAPK and CaM kinase IV started early after LTP induction and decreased within 10 min, whereas CREB phosphorylation gradually increased. Induction of c-Fos protein increased after 30 min during LTP, concomitantly with CREB phosphorylation. The experiments with inhibitors indicated that MAPK and CaM kinase IV were involved in phosphorylation of CREB.

\section{Conclusion}

Since the discovery of LTP by Bliss et al. in 1973, many investigators have been studying its molecular mechanisms. Since a variety of findings and hypotheses were presented, it would be agreed that the events in postsynaptic neurons are activated to produce LTP induction and maintenance. For LTP induction, NMDA glutamate receptor activation, subsequent $\mathrm{Ca}^{2+}$ entry, and CaM kinase II activation are important, while for LTP maintenance, a stimulation of gene expression is necessary. On the basis of the studies on inhibitors and mutant mice, the involvement of PKC in LTP induction was proposed. However, the role of PKC has not been confirmed at present.

It is still controversial that LTP is closely related to short and long memory. Many studies have been done to prove it. For example, animals in which LTP was sufficiently expressed by electric stimulation of the dentate gyrus of the hippocampus showed lower ability for learning. Administration of NMDA glutamate receptor antagonists impaired LTP induction and the ability of spatial learning.

Neuronal plasticity of animals is essential for their daily lives because they must adapt to changes in their outside environment. Several types of neuronal plasticity were elucidated by creation of models. The molecular mechanism of each model has been studied and elucidated, as shown in Table 2. Further studies will be done to study LTP in the hippocampus, which is a model for learning and memory of animals.

\section{Acknowledgments}

Our studies cited in the present review were performed at the Department of Pharmacology, Kumamoto University School of Medicine. I would like to thank all of my colleagues in the Department for their efforts and cooperation during the course of these investigations.

\section{References}

1 Ohta Y, Ohba T, Fukunaga K, Miyamoto E. Serum and growth factors rapidly elicit phosphorylation of the $\mathrm{Ca}^{2+} /$ calmodulindependent protein kinase II in intact quiescent rat 3Y1 cells. J Biol Chem. 1988;263:11540-11547.

2 Yamakawa T, Fukunaga K, Higashida H, Miyamoto E. Activation of $\mathrm{Ca}^{2+} /$ calmodulin-dependent protein kinase II by stimulation with bradykinin in neuroblastoma $\mathrm{x}$ glioma hybrid NG108-15 cells. Brain Res. 1992;597:220-226.

3 Fukunaga K, Soderling TR, Miyamoto E. Activation of $\mathrm{Ca}^{2+} /$ calmodulin-dependent protein kinase II and protein kinase $\mathrm{C}$ by glutamate in cultured rat hippocampal neurons. J Biol Chem. 1992;267:22527-22533.

4 Kurino M, Fukunaga K, Ushio Y, Miyamoto E. Activation of mitogen-activated protein kinase in cultured rat hippocampal neurons by stimulation of glutamate receptors. J Neurochem. 1995;65:1282-1289.

5 Ohmitsu M, Fukunaga K, Yamamoto H, Miyamoto E. Phosphorylation of myristoylated alanine-rich protein kinase $\mathrm{C}$ substrate by mitogen-activated protein kinase in cultured rat hippocampal neurons following stimulation of glutamate receptors. J Biol Chem. 1999;274:408-417.

6 Kasahara J, Fukunaga K, Miyamoto E. Activation of $\mathrm{Ca}^{2+}$ /calmodulin-dependent protein kinase IV in cultured rat hippocampal neurons. J Neurosci Res. 2000;59:594-600.

7 Kasahara J, Fukunaga K, Miyamoto E. Differential effects of a 
calcineurin inhibitor on glutamate-induced phosphorylation of $\mathrm{Ca}^{2+} /$ calmodulin-dependent protein kinases in cultured rat hippocampal neurons. J Biol Chem. 1999;274:9061-9067.

8 Uezu A, Fukunaga K, Kasahara J, Miyamoto E. Activation of $\mathrm{Ca}^{2+} /$ calmodulin-dependent protein kinase $\mathrm{I}$ in cultured rat hippocampal neurons. J Neurochem. 2002;82:585-593.

9 Fukunaga K, Stoppini L, Miyamoto E, Muller D. Long-term potentiation is associated with an increased activity of $\mathrm{Ca}^{2+} /$ calmodulin-dependent protein kinase II. J Biol Chem. 1993;268:7863-7867.

10 Fukunaga K, Muller D, Miyamoto E. Increased phosphorylation of $\mathrm{Ca}^{2+}$ /calmodulin-dependent protein kinase II and its endogenous substrates in the induction of long-term potentiation. J Biol Chem. 1995;270:6119-6124.

11 Liu J, Fukunaga K, Yamamoto H, Nishi K, Miyamoto E. Differential roles of $\mathrm{Ca}^{2+} /$ calmodulin-dependent protein kinase II and mitogen-activated protein kinase activation in hippocampal long-term potentiation. J Neurosci. 1999;19:8292-8299.

12 Fukunaga K, Muller D, Ohmitsu M, Bakó E, DePaoli-Roach AA, Miyamoto E. Decreased protein phosphatase 2A activity in hippocampal long-term potentiation. J Neurochem. 2000;74: 807-817.

13 Kasahara J, Fukunaga K, Miyamoto E. Activation of calcium /calmodulin-dependent protein kinase IV in long term potentiation in the rat hippocampal CA1 region. J Biol Chem. 2001;276:24044-24050.

14 Yano S, Fukunaga K, Ushio Y, Miyamoto E. Activation of $\mathrm{Ca}^{2+} /$ calmodulin-dependent protein kinase II and phosphorylation of intermediate filament proteins by stimulation of glutamate receptors in cultured rat cortical astrocytes. J Biol Chem. 1994;269:5428-5439.

15 Yano S, Fukunaga K, Takiguchi M, Ushio Y, Mori M, Miyamoto E. Regulation of CCAAT/enhancer binding protein family members by stimulation of glutamate receptors in cultured rat cortical astrosytes. J Biol Chem. 1996;271:23520 23527.

16 Yanagihara N, Toyohira Y, Yamamoto H, Ohta Y, Tsutsui M, Miyamoto E, et al. Occurrence and activation of $\mathrm{Ca}^{2+} /$ calmodulindependent protein kinase II and its endogenous substrates in bovine adrenal medullary cells. Mol Pharmacol. 1994;46:423430.

17 Tsutsui M, Yanagihara N, Miyamoto E, Kuroiwa A, Izumi F. Correlation of activation of $\mathrm{Ca}^{2+} /$ calmodulin-dependent protein kinase II with catecholamine secretion and tyrosine hydroxylase activation in cultured bovine adrenal medullary cells. Mol Pharmacol. 1994;46:1041-1047.

18 Yanagihara N, Oishi Y, Yamamoto H, Tsutsui M, Kondoh J, Sugiura $\mathrm{T}$, et al. Phosphorylation of chromogranin $\mathrm{A}$ and catecholamine secretion stimulated by elevation of intracellular $\mathrm{Ca}^{2+}$ in cultured bovine adrenal medullary cells. J Biol Chem. 1996;271:17463-17468.

19 Tashima K, Yamamoto H, Setoyama C, Ono T, Miyamoto E. Overexpression of $\mathrm{Ca}^{2+} /$ calmodulin-dependent protein kinase II inhibits neurite outgrowth of PC12 cells. J Neurochem. 1996;66:57-64.

20 Matsumoto K, Fukunaga K, Miyazaki J, Shichiri M, Miyamoto E. $\mathrm{Ca}^{2+} /$ calmodulin-dependent protein kinase II and synapsin Ilike protein in mouse insulinoma MIN6 cells. Endocrinology. 1995;136:3784-3793.

21 Ebihara K, Fukunaga K, Matsumoto K, Shichiri M, Miyamoto
E. Cyclosporin A stimulation of glucose-induced insulin secretion in MIN6 cells. Endocrinology. 1996;137:5255-5263.

22 Matsumoto K, Ebihara K, Yamamoto H, Tabuchi H, Fukunaga $\mathrm{K}$, Yasunami $\mathrm{M}$, et al. Cloning from insulinoma cells of synapsin I associated with insulin secretory granules. J Biol Chem. 1999;274:2053-2059.

23 Tabuchi H, Yamamoto H, Matsumoto K, Ebihara K, Takeuchi $\mathrm{Y}$, Fukunaga K, et al. Regulation of insulin secretion by overexpression of $\mathrm{Ca}^{2+} /$ calmodulin-dependent protein kinase II in insulinoma MIN6 cells. Endocrinology. 2000;141:2350-2360.

24 Kanasaki H, Fukunaga K, Takahashi K, Miyazaki K, Miyamoto E. Mitogen-activated protein kinase activation by stimulation with thyrotropin-releasing hormone in rat pituitary GH3 cells. Biol Reprod. 1999;61:319-325.

25 Kanasaki H, Fukunaga K, Takahashi K, Miyazaki K, Miyamoto E. Involvement of p38 mitogen-activated protein kinase activation in bromocriptine-induced apoptosis in rat pituitary GH3 cells. Biol Reprod. 2000;62:1486-1494.

26 Munir I, Fukunaga K, Miyazaki K, Okamura H, Miyamoto E. Mitogen-activated protein kinase activation and regulation of cyclooxygenase 2 expression by platelet-activating factor and hCG in human endometrial adenocarcinoma cell line HEC-1B. J Reprod Fertil. 1999;117:49-59.

27 Munir I, Fukunaga K, Kanasaki H, Miyazaki K, Ohba T, Okamura H, et al. Expression of cyclo-oxygenase 2 by prostaglandin E2 in human endometrial adenocarcinoma cell line HEC-1B. Biol Reprod. 2000;63:933-941.

28 Kanasaki H, Yonehara T, Yamada Y, Takahashi K, Hata K, Fujiwaki R, et al. Regulation of gonadotropin alpha subunit gene expression by dopamine D2 receptor agonist in clonal mouse gonadotroph alpha T3-1 cells. Biol Reprod, 2002;67:1218-1224.

29 Yonehara T, Yamada Y, Kanasaki H, Yamamoto H, Fukunaga K, Miyazaki K, et al. Characterization of alpha T3-1 cells stably tranfected with luteinizing hormone beta-subunit complementary deoxyribonucleic acid. Endocrine J. 2003;50:341-354.

30 Yamada Y, Yamamoto H, Yonehara T, Kanasaki H, Nakanishi H, Miyamoto E, et al. Differential activation of the luteinizing hormone beta-subunit promotor by activin and gonadotropinreleasing hormone: a role for mitogen-activated protein kinase signaling pathway in L beta T2 gonadotrophs. Biol Reprod. 2004;70:236-243.

31 Wiesel TN, Hubel DH. Single-cell responses in striate cortex of kittens deprived of vision in one eye. J Neurophysiol. 1963;26: 1003-1017.

32 Dale N, Schacher S, Kandel ER. Long-term facilitation in Aplysia involves increase in transmitter release. Science. 1988;239:282-285.

33 Rogan MT, Stäubli UV, LeDoux JE. Fear conditioning induces associative long-term potentiation in the amygdala. Nature. 1997;390:604-606.

34 Bliss TVP, Lomo T. Long-lasting potentiation of synaptic transmission in the dentate area of the anaesthetized rabbit following stimulation of the perform path. J Physiol. 1973;232: 331-356.

35 Karachot L, Shirai Y, Vigot R, Yamamori T, Ito M. Induction of long-term depression in cerebeller Purkinje cells requires a rapidly turned over protein. J Neurophysiol. 2001;86:280-289.

36 Matsuoka M, Kaba H, Mori Y, Ichikawa M. Synaptic plasticity in olfactory memory formation in female mice. NeuroReport. 1997;8:2501-2504. 
37 Kishimoto Y, Kawahara S, Mori H, Mishina M, Kirino Y. Longtrace interval eyeblink conditioning is impaired in mutant mice lacking NMDA receptor subunit e1. Eur J Neurosci. 2001;13: 1221-1227.

38 Miyamoto E, Fukunaga K. A role of $\mathrm{Ca}^{2+} /$ calmodulin-dependent protein kinase II in the induction of long-term potentiation in hippocampal CA1 area. Neurosci Res. 1996;24:117-122.

39 Bliss TVP, Collingridge GL. A synaptic model of memory: long-term potentiation in the hippocampus. Nature. 1993;361: 31-39.

40 Miyamoto E, Liu J, Fukunaga K, Muller D. Involvement of CaM kinase II and mitogen-activated protein kinase in hippocampal long-term potentiation. In: Tanaka C, McGeer PL, Ihara Y, editors. Neuroscientific basis of dementia. Basel, Switzerland: Birkhäuser Verlag; 2001. p. 49-57.

41 Lisman J, Schulman H, Cline H. The molecular basis of CaMKII function in synaptic and behavioral memory. Nature Rev Neurosci. 2002;3:175-190.

42 Hudmon A, Schulman H. Neural $\mathrm{Ca}^{2+} /$ calmodulin-dependent protein kinase II: the role of structure and autoregulation in cellular function. Annu Rev Biochem. 2002;71:473-510.

43 Miyamoto E, Fukunaga K. [Molecular mechanism of long-term potentiation in hippocampus.] Protein Nucleic Acid Enzyme. 2004;49:391-397. (in Japanese)

44 Worgotter F, Porr B. Temporal sequence learning, prediction, and control: a review of different models and their relation to biological mechanisms. Neural Computation. 2005;17:245-319.

45 Gubellini P, Ben-Ari Y, Gaiarsa JL. Endogenous neurotrophins are required for the induction of GABAergic long-term potentiation in the neonatal rat hippocampus. J Neurosci, 2005;25:57965802.

46 Costa-Mattioli M, Gobert D, Harding H, Herdy B, Azzi M, Bruno M, et al. Translational control of hippocampal synaptic plasticity and memory by the eIF2 alpha kinase GCN2. Nature. 2005;436:1166-1173.

47 Collingridge GL, Kehl SJ, McLennan H. Activation of NMDA receptors blocks GABAergic inhibition in an in vitro model of epilepsy. J Physiol. 1983;344:33-46.

48 Malenka RC, Lancaster B, Zucker RS. Temponal limits on the rise in calcium required for the induction of long-term potentiation. Neuron. 1992;9:121-128.

49 Malenka RC, Kauer JA, Perkel DJ, Mauk MD, Kelly PT, Nicoll RA, et al. An essential role for postsynaptic calmodulin and protein kinase activity in long-term potentiation. Nature. 1989;340:554-557.

50 Malinow R, Schulman H, Tsien RW. Inhibition of postsynaptic
PKC or CaMKII blocks induction but not expression of LTP. Science. 1989;245:862-866.

51 Ito I, Hidaka H, Sugiyama H. Effects of KN-62, a specific inhibitor of calcium/calmodulin-dependent protein kinase II, on long-term potentiation in the rat hippocampus. Neurosci Lett. 1991;121:119-121.

52 Sakimura K, Kutsuwada T, Ito I, Manabe T, Takayama C, Kushiya E, et al. Reduced hippocampal LTP and spatial learning in mice lacking NMDA receptor e1 subunit. Nature. 1995;373: 151-155.

53 McHugh TJ, Blum KI, Tsien JZ, Tonegawa S, Wilson MA. Impaired hippocampal representation of space in CA1-specific NMDAR1 knockout mice. Cell. 1996;87:1339-1349.

54 Silva AJ, Stevens CF, Tonegawa S, Wang Y. Deficient hippocampal long-term potentiation in $\alpha$-calcium-calmodulin kinase II mutant mice. Science. 1992;257:201-206.

55 Silva AJ, Paylor R, Wehner JM, Tonegawa S. Impaired spatial learning in a-calcium-calmodulin kinase II mutant mice. Science. 1992;257:206-211.

56 Abeliovich A, Chen C, Goda Y, Silva AJ, Stevens CF, Tonegawa S. Modified hippocampal long-term potentiation in PKCg mutant mice. Cell. 1993;75:1263-1271.

57 Grant SG, O’Dell TJ, Karl KA, Stein PL, Soriano P, Kandel ER. Impaired long-term potentiation, spatial learning, and hippocampal development in fyn mutant mice. Science. 1992;258: 1903-1910.

58 Bourtchuladze R, Frenguelli B, Blendy J, Cioffi D, Schutz G, Silva AJ. Deficient long-term memory in mice with a targeted mutation of the cAMP-responsive element binding protein. Cell. 1994;79:59-68.

59 Tang Y-P, Shimizu E, Dube GR, Rampon C, Kerchner GA, Zuo $\mathrm{M}$, et al. Genetic enhancement of learning and memory in mice. Nature. 1999;401:63-69.

60 Shimizu E, Tang Y-P, Rampon C, Tsien JZ. NMDA receptordependent synaptic reinforcement as a crucial process for memory consolidation. Science. 2000;290:1170-1174.

61 English JD, Sweatt JD. Activation of p42 mitogen-activated protein kinase in hippocampal long-term potentiation. J Biol Chem. 1996;271:24329-24332.

62 English JD, Sweatt JD. A requirement for the mitogen-activated protein kinase cascade in hippocampal long term potentiation. J Biol Chem. 1997;272:19103-19106.

63 Luscher C, Nicoll RA, Malenka RL, Muller D. Synaptic plasticity and dynamic modulation of the postsynaptic membrane. Nature Neurosci. 2000;3:545-550. 